J. Dairy Sci. 99:2979-2985

http://dx.doi.org/10.3168/jds.2015-9942

(C) American Dairy Science Association ${ }^{\circledR}, 2016$.

\title{
The effect of bovine somatotropin on the cost of producing milk: Estimates using propensity scores
}

\author{
Loren W. Tauer ${ }^{1}$ \\ Charles H. Dyson School of Applied Economics and Management, College of Agricultural and Life Sciences, Cornell University, NY 14853
}

\begin{abstract}
Annual farm-level data from New York dairy farms from the years 1994 through 2013 were used to estimate the cost effect from bovine somatotropin (bST) using propensity score matching. Cost of production was computed using the whole-farm method, which subtracts sales of crops and animals from total costs under the assumption that the cost of producing those products is equal to their sales values. For a farm to be included in this data set, milk receipts on that farm must have comprised $85 \%$ or more of total receipts, indicating that these farms are primarily milk producers. Farm use of bST, where $25 \%$ or more of the herd was treated, ranged annually from 25 to $47 \%$ of the farms. The average cost effect from the use of bST was estimated to be a reduction of $\$ 2.67$ per $100 \mathrm{~kg}$ of milk produced in 2013 dollars, although annual cost reduction estimates ranged from statistical zero to $\$ 3.42$ in nominal dollars. Nearest neighbor matching techniques generated a similar estimate of $\$ 2.78$ in 2013 dollars. These cost reductions estimated from the use of bST represented a cost savings of $5.5 \%$ per kilogram of milk produced. Herd-level production increase per cow from the use of bST over $20 \mathrm{yr}$ averaged $1,160 \mathrm{~kg}$.
\end{abstract}

Key words: bovine somatotropin, matching, propensity score, rbST, treatments

\section{INTRODUCTION}

The compound recombinant bST has been commercially available to US dairy producers since 1994. Monsanto (St. Louis, MO) marketed bST beginning in 1994 under the trademark Posilac, but sold the technology in 2008 to Eli Lilly's Animal Health Division, Elanco Animal Health (Greenfield, IN). The use of bST in lactating cows has been controversial, with opponents questioning the effect on cow health and milk composition, whereas proponents have argued it allows

Received June 10, 2015.

Accepted January 6, 2016.

${ }^{1}$ Corresponding author: lwt1@cornell.edu producing milk with fewer resources and reduces the greenhouse gas impact associated with milk production. Discussions of these arguments can be found in Dohoo et al. (2003), Collier et al. (1991), and Capper et al. (2008). St-Pierre et al. (2014) completed a recent meta-analysis of the research results addressing bST. The purpose of the current study is not to revisit those debates, which have been extensive, but to simply address one question: what has been the effect of bST on the cost of producing milk? To provide an answer, 20 yr of data on a large number of New York dairy farms was used to estimate the cost effect per $100 \mathrm{~kg}$ of milk produced with the use of bST compared with no use of bST using propensity score matching (PSM).

\section{MATERIALS AND METHODS}

The use of program evaluation methods, or treatment models, has become extensive in the literature, where researchers have been interested in the performance of treatments such as education, training, vaccination, or a new technology such as bST (Rubin, 1974; Imbens, 2000; Heckman and Navarro-Lozano, 2004). Often it is not cost effective or ethical to carry out a controlled experiment to ascertain the effect of a treatment. Thus, it is necessary to observe the effect of the treatment in the field by comparing the performance of those who received the treatment to those who did not receive the treatment. Field results can also differ significantly from experimental results under controlled conditions (Dehejia and Wahba, 2002). If participation is voluntary and not random, self-selection bias becomes an issue which may influence empirical estimates of the effect of the treatment (Imbens and Wooldridge, 2009). For example, it is generally presumed that farmers who adopt a new technology should see an improvement in their welfare or quality of life as measured by an income or leisure variable. However, because farmers themselves decide whether to adopt a new technology in a noncontrolled experiment, it may be that more highly educated and higher-income farmers are the ones who adopt, resulting in self-selection bias with an over estimate of the adoption effect. Mendola (2007) in- 
vestigated agricultural adoption and poverty reduction in rural Bangladesh, controlling for self-selection, and determined that resource-poor farmers can improve their incomes by adopting improved seed genetics. It may also be possible that those who elect to use bST on their farm may have generated a lower cost per unit of production than those who elected not to use bST, or vice versa. Simply comparing bST users to non-bST users can lead to biased effect estimates without addressing selection bias.

A large number of techniques have been developed to estimate treatment effects. Two reviews are available from Imbens and Wooldridge (2009) and Khandker et al. (2010). In the bST effect literature, the treatment estimators that have been used include difference in differences estimation (Tauer and Knoblauch, 1997), instrumental variables (McBride et al., 2004), Heckman self-selection models (Stefanides and Tauer, 1999; Foltz and Chang, 2002; Gillespie et al., 2010), switching regression (Tauer, 2005; An, 2013), and nearest neighbor matching models (Tauer, 2009). The empirical results of these articles have been mixed with earlier studies using initial years of bST use data finding bST not profitable, whereas later studies found bST to generally be profitable. In this article, PSM, introduced by Rosenbaum and Rubin (1983), is used to measure the cost of production reduction from the use of bST on the farm. A comprehensive guide to using PSM can be found in Caliendo and Kopeinig (2008).

Treatment estimation begins with a definition of an indicator variable $\left(\mathbf{D}_{\mathbf{i}}\right)$, which equals 1 if individual $\mathrm{i}$ receives treatment and zero otherwise. The potential treatment outcomes are then measured as $\mathrm{Y}_{\mathrm{i}}\left(\mathrm{D}_{\mathrm{i}}\right)$ for each individual $\mathrm{i}$, where $\mathrm{i}=1, \ldots, \mathrm{N}$, with $\mathrm{N}$ denoting individuals, and $\mathrm{Y}$ the performance measure. The treatment effect $\left(\tau_{\mathrm{i}}\right)$ for an individual i can be estimated as: $\tau_{\mathrm{i}}=\mathrm{Y}_{\mathrm{i}}(1)-\mathrm{Y}_{\mathrm{i}}(0)$. The problem, however, is that only one of the potential outcomes is observed for each individual i. The unobserved outcome is referred to as a counterfactual. It is necessary to arrive at an estimate of a counterfactual for $\mathrm{Y}_{\mathrm{i}}(1)$ or $\mathrm{Y}_{\mathrm{i}}(0)$ depending upon whether the individual received the treatment (1) or did not receive the treatment (0). Propensity score matching techniques allow devising that counterfactual.

Propensity score matching requires estimating the probability that an individual received the treatment conditional upon characteristics of that individual. Logistic regression is used to estimate a propensity score where the dependent variable is equal to 1 if the individual received the treatment, 0 otherwise, and the independent variables are variables that are expected to determine treatment. The logistic regression estimates are used to predict the probability of each individual being treated even if they were not treated. This prob- ability is referred to as the propensity score. Each farm that selected the treatment is then matched with a farm that did not select the treatment using the criterion that the probability of treatment selection is similar between the 2 farms; this then becomes the counterfactual. The process mimics random placement. Because the propensity score or probability is a single variable, matching is straightforward and simply entails finding the observation with the closest score. This is one-toone matching; one-to-more than one matching was not used given the large number of one-to-one matches that were available. The difference in the performance variable provides an estimate of the treatment effect, $\tau_{i}$, which is then averaged over all matches; treatment in our case was use of bST. For estimation, Stata software (version 13; StataCorp LP, College Station, TX), procedure "teffects psmatch," was used

As stated by Khandker et al. (2010) in a World Bank Handbook on estimating treatment effects, "The validity of propensity score matching depends on two conditions: (a) conditional independence (namely, that unobserved factors do not affect participation) and (b) sizable common support or overlap in propensity scores across the participant and nonparticipant samples." The first requirement is that the factors selected to estimate the propensity score explains treatment and no variables are omitted. The second requires overlap of the probability distribution of the propensity score so that treatment farms can be matched with nontreatment farms based on similar propensity scores.

Cornell University completes an annual dairy farm business survey in which, although voluntary, many farmers participate over multiple years. The survey collects detailed cost and revenue as well as assets and liabilities data to construct net farm income, net worth, and cash flow statements. Data on yields and characteristics of the farm are also collected. These data are primarily used for individual farm analysis, allowing individual operators to compare their farm performance to benchmark values from similar farms. This is not a random sample and generally includes farms of above performance irrespective of farming practices used on those farms. These are full-time dairy farms, because to be included milk sales must compose $85 \%$ or more of total farm receipts.

Since 1994, when bST first became commercially available, data on bST use have been collected. From 1994 through 2002, each year farmers were asked to check a category box indicating the percentage use of bST as no use, discontinued use, 0 to $25 \%$ of the herd treated, 25 to $75 \%$ of the herd treated, or $75 \%$ or more of the herd treated during the year. A measure of $100 \%$ would be treating all cows every $14 \mathrm{~d}$ throughout the lactation, beginning $62 \mathrm{~d}$ after calving and ceasing at 
the end of lactation. Data were not available on the specific cows that were treated with bST. We presume farmers treated the cows they believed would be the best candidates.

Beginning in the year 2003, the bST use question was changed so that farmers were asked to indicate the actual percentage of the herd treated, with no use again, or discontinued use as additional response options. Beginning in 2007, farm expenditure on bST was collected and recorded as a separate expense item. The percentage use on the herd was also asked in 2007, but a couple of years later became a voluntary question. This change in data collection protocol over the years required a modification to measuring bST use to be consistent across the years.

Expenditure data were not collected until 2007; thus, that data were not available in the early years, and percentage use reporting dropped off significantly by the year 2009, only providing bST expenditure data after that year. Some farms also reported bST use as a low percentage of the herd treated with a corresponding low expenditure on bST, questioning whether they should be coded as bST users. Thus, it was decided to define bST use as occurring if $25 \%$ or more of the herd were treated, given that was the breakpoint in the categorical question in the early years of the data collection. The number of farmers who responded to the optional question asking for the specific percentage of the herd treated fell in the last years of the survey, so it was necessary to determine a percentage estimate for these later years when only expenditure on bST was collected. Using data from the years 2007 to 2011, when both percentage and expenditures were reported, the percentage use was regressed on bST expenditure to obtain a relationship to convert bST expenditures per cow into a percentage of herd use. With no intercept modeled, because zero expenditure on bST should mean zero percent of the herd treated, an estimated coefficient of 0.90 was estimated with a t-statistic of 49.75 from 124 observations. This meant that any bST expenditure of $\$ 27$ or more per cow per year translated into $25 \%$ or more of the herd treated with bST, as 0.90 multiplied by 27 results in $25 \%$. This conversion was done in those years when the dollar expenditure on bST expenditure was collected.

Farms that indicated that they did not use bST were classified as not using bST. Farms that discontinued the use of bST during a year or used it on less than $25 \%$ of the herd were removed from the analysis. Table 1 lists the number of farms participating in the New York Dairy Farm Business Summary each year from 1994 through 2013 along with the number of those farms that used bST or did not use bST according to this classification of bST use. The peak use of bST was in 2002 when $47 \%$ of the farms used bST.

A performance variable was necessary to determine the farm effect of using bST. Net farm income could be a candidate, but it excludes as expenses the opportunity cost of equity and unpaid labor, and thus would be a biased measure conditional on the proportion of assets funded by equity and of unpaid operator and family labor to total labor. More appropriate would be the

Table 1. Annual number of observations from the New York Dairy Farm Business Summary, non-bST users, minor bST users, and bST users ${ }^{1}$

\begin{tabular}{|c|c|c|c|c|c|}
\hline Year & $\begin{array}{l}\text { Number } \\
\text { of farms }\end{array}$ & $\begin{array}{c}\text { Non-bST } \\
\text { users }\end{array}$ & $\begin{array}{l}\text { Minor bST } \\
\text { users }\end{array}$ & $\begin{array}{l}\text { bST } \\
\text { users }\end{array}$ & $\begin{array}{l}\text { Percent } \\
\text { bST users }\end{array}$ \\
\hline 1994 & 324 & 171 & 49 & 104 & 32 \\
\hline 1995 & 329 & 156 & 63 & 110 & 33 \\
\hline 1996 & 307 & 156 & 46 & 105 & 34 \\
\hline 1997 & 280 & 133 & 45 & 102 & 36 \\
\hline 1998 & 324 & 145 & 47 & 132 & 41 \\
\hline 1999 & 314 & 142 & 33 & 139 & 44 \\
\hline 2000 & 294 & 129 & 35 & 130 & 44 \\
\hline 2001 & 228 & 107 & 22 & 99 & 43 \\
\hline 2002 & 219 & 103 & 13 & 103 & 47 \\
\hline 2003 & 207 & 102 & 18 & 87 & 42 \\
\hline 2004 & 199 & 109 & 14 & 76 & 38 \\
\hline 2005 & 228 & 127 & 20 & 81 & 36 \\
\hline 2006 & 243 & 168 & 15 & 60 & 25 \\
\hline 2007 & 257 & 146 & 17 & 94 & 37 \\
\hline 2008 & 227 & 125 & 8 & 94 & 41 \\
\hline 2009 & 248 & 143 & 10 & 95 & 38 \\
\hline 2010 & 242 & 143 & 12 & 87 & 36 \\
\hline 2011 & 211 & 126 & 26 & 59 & 28 \\
\hline 2012 & 168 & 112 & 8 & 48 & 29 \\
\hline 2013 & 175 & 122 & 5 & 48 & 27 \\
\hline
\end{tabular}

${ }^{1}$ bST use was defined as using on $25 \%$ or more of the herd. Non-bST was defined as not using bST anytime during the year. Minor bST was defined as using on less than $25 \%$ of the herd or discontinued bST use during the year. 
cost of producing milk per unit of output. Because bST increases output but also requires additional inputs, such as feed and labor to produce the additional milk, the total cost of producing $100 \mathrm{~kg}$ of milk was used as the performance variable. Total cost is better than operating cost per $100 \mathrm{~kg}$ of milk because by increasing output the use of bST can spread overhead cost over more milk production. The total cost per unit of milk produced also reflects the reduction in all the resources used to produce a unit of milk, which in a competitive market would be transmitted as lower milk prices to consumers. The total cost of producing milk includes the operating costs of producing milk plus depreciation on machinery and buildings, the value of unpaid family labor, and the value of operators' labor and management, and is used as computed and reported in the Dairy Farm Business Summary data set (Knoblauch, et. al, 2012). Another separate performance variable used was annual milk production per cow to determine the empirical output effect of bST.

Farm characteristics that have been associated with bST use from previous studies include the number of cows on the farm, the milking system (use of a parlor of any type vs. none parlor use), type of barn (freestall types vs. stanchion types), the age of the principal operator, and the education (in years) of the operator (Barham et al., 2000; Foltz and Chang, 2002; Tauer, 2009). These variables were used in a logit function to estimate the probability of bST use with estimates reported in Table 2 for the entire 20 -yr period, although annual estimates were used in annual matching. Because overlap of probability distributions of bST use and nonuse is necessary for successful PSM, farms with more than 1,000 cows were dropped from the analysis because most large farms used bST.

Validity of PSM requires that the observed variables predict the adoption of bST and that no unobservables influence this adoption (Khandker et al., 2010). The variables selected to explain adoption were previously found to explain bST adoption using earlier farm data

Table 2. Logistic regression of bST use by New York Dairy Farm Business Summary farms over the years 1994 through 2013 with number of cows $<1,000^{1}$

\begin{tabular}{lrcr}
\hline Variable & Estimate & SE & \multicolumn{1}{c}{$\mathrm{z}$} \\
\hline Cows (1,000) & 2.604 & 0.198 & 13.17 \\
Milking system & 0.433 & 0.158 & 2.74 \\
Barn type & 0.652 & 0.150 & 4.36 \\
Operator age & -0.014 & 0.003 & -5.20 \\
Operator education & 0.141 & 0.011 & 12.51 \\
Constant & -2.961 & 0.162 & -18.28
\end{tabular}

${ }^{1} \mathrm{n}=4,209 ;$ likelihood ratio $\chi^{2}=835(P=0.00)$; McFadden's pseudo $\mathrm{R}^{2}=0.15 ; 20$ separate annual logistic regressions not shown were used to estimate annual bST treatment effects by propensity score matching.
(Stefanides and Tauer, 1999). However, given that the data are a panel of farms, the influence of any unobservables might be extracted by exploiting the panel nature of the data by including fixed or random effects. A likely model to use rather than PSM might then be a difference-in-difference estimator. Difference-in-difference estimation uses data from 2 consecutive years where all units are untreated during the base year, whereas controls remain untreated the second year (Khandker et al., 2010). Although the current data are a panel data set, with a series of base and second-year data, the difference-in-difference estimation was not used for several reasons. First, there may be a learning curve to the use of bST because both Tauer and Knoblauch (1997) and Foltz and Chang (2002), who respectively used data from 2 adjacent years from New York and Connecticut dairy farms, found no profitability effect from the use of bST. Using additional years of panel data may assist in determining effect, but the panel is unbalanced and many farms did not participate in adjacent years. Second, most farms, when they adopted bST, continued to use bST every year, although some disadoption occurred in the later years and limited the number of adoption changes. Difference-in-difference estimation requires observations from the same farm that used and then did not use bST (or vice versa). Table 3 shows that $93 \%$ of the farms that used bST in any year also used bST the following year if they participated in the survey the following (second) year, whereas $96 \%$ of the farms that did not use bST in any year also did not use bST in the following year. On average, only 4 survey farms began using bST in a following year if they participated in the survey the preceding year. Because of these limitations to the implementation of differencein-difference estimation using fixed or random effects, we assumed that biases from unobservables were not significant in the propensity score estimation.

\section{RESULTS AND DISCUSSION}

The annual results reported in Table 4 show that the cost effect from the use of bST varied by year, from the largest reduction of $\$ 3.42$ per $100 \mathrm{~kg}$ of milk produced in both 2004 and 2008, to the lowest reduction of $\$ 0.24$ per $100 \mathrm{~kg}$ of milk produced in 2009. These estimated

Table 3. Percentage of farms using and not using bST in adjacent years

\begin{tabular}{lcc}
\hline & \multicolumn{2}{c}{ bST use in yr 1 } \\
\cline { 2 - 3 } bST use in yr 2 & No & Yes \\
\hline No & 96.16 & 3.84 \\
Yes & 6.72 & 93.28 \\
\hline
\end{tabular}


Table 4. Cost reduction per kilogram of milk produced from the use of bST on $25 \%$ or more of the herd ${ }^{1}$

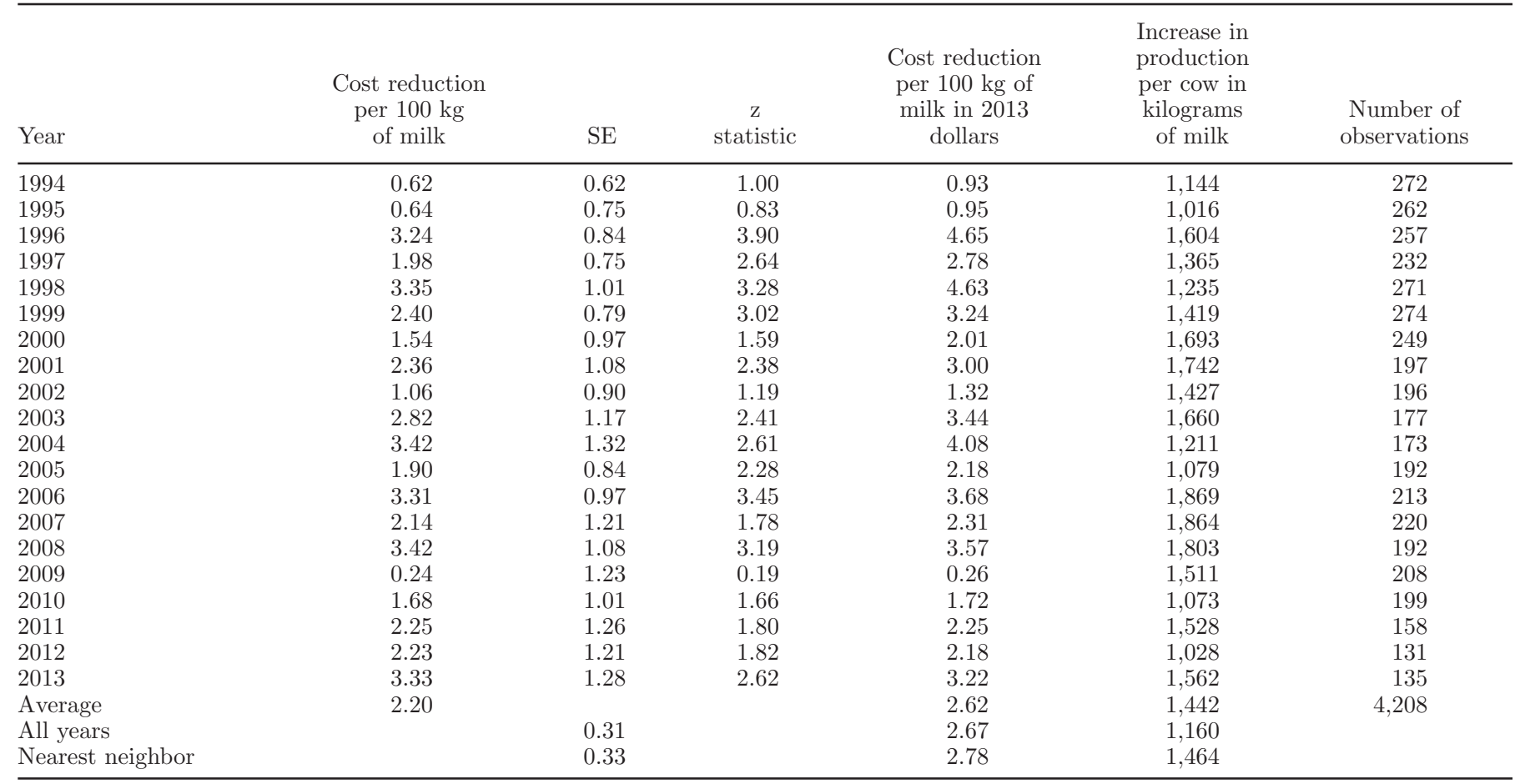

${ }^{1}$ Estimation by propensity score matching using participants in the New York Dairy Farm Business Summary Program. Farms using bST on less than $25 \%$ of the herd were excluded from the analysis. Farms with more than 1,000 cows were also excluded due to overlap issues. Propensity scores were estimated as a logit function of the number of cows, use of a milking parlor, freestall barn, age of principal operator, and education of principal operator. Production increases from bST were all statistically significant at the $P=0.999$ level. Estimation for each year was in current dollars. All-years estimation was in 2013 dollars. The command "teffects psmatch" in Stata (StataCorp LP, College Station, TX) was used. Nearest neighbor matching "teffects nnmatch" in Stata used the same variables as the logit propensity score with cows $<1,000$ to be consistent, with exact matching by year.

cost reductions were statistically different from zero in most years $(P>0.90)$, except for the first 2 yr of use, 1994 and 1995, and in the years 2000, 2002, and 2009. These cost reductions reflect increased milk production from the use of bST, which allows spreading total costs over more milk production even with the additional inputs required to use bST.

The data are an unbalanced panel and, just as farm total costs vary by farm each year, any cost effect from the use of bST would also be expected to vary by year depending upon the farms in the data each year and the cost of inputs. Figure 1 plots the bST cost reduction by year and the locally weighted regression of that cost reduction on the year variable using a bandwidth of 0.8 (Cleveland, 1979). Many of the early bST research articles using early years of bST use concluded that the use of bST was not profitable statistically (Tauer and Knoblauch, 1997; Foltz and Chang, 2002), and those empirical results are verified here by the first $2 \mathrm{yr}$ of results, which statistically show no cost savings from the use of bST. The use of bST results in a reduction in cost per unit of output beginning the third year,

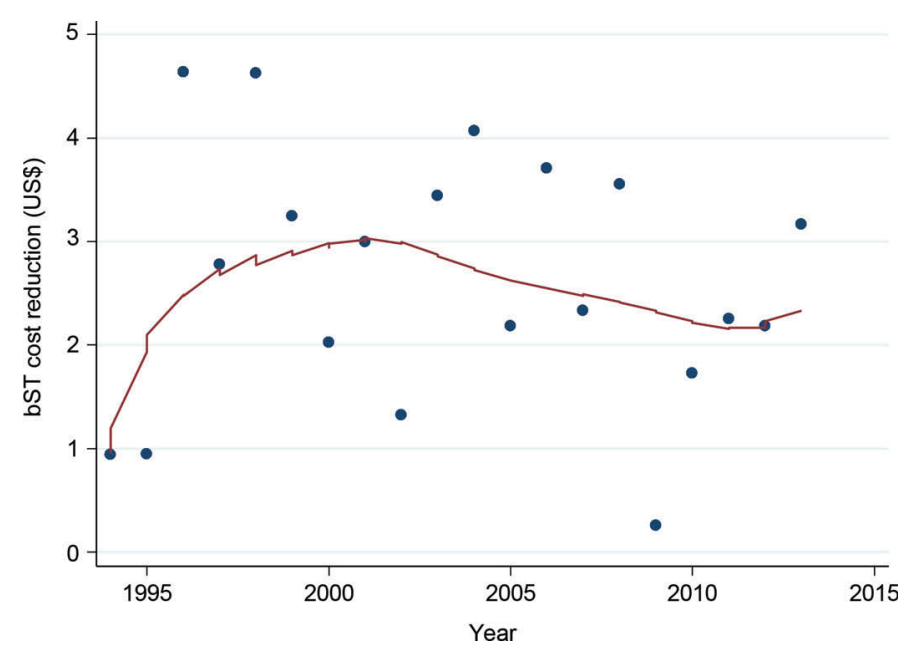

Figure 1. Nonparametric regression of bST cost reduction per 100 $\mathrm{kg}$ of milk produced by year (in 2013 dollars) using locally weighted regression with a bandwidth of 0.8 . Color version available online. 
possible reflecting learning to use after the initial $2 \mathrm{yr}$ of use, with a smaller reduction in costs in later years.

Consumer preference for milk not produced using bST, transmitted through retailers and milk collection organizations, caused some farms to cease the use of bST during the later years regardless of bST profitability on the farm to continue to supply milk through those organizations. In some instances farmers were paid a price premium to cease the use of bST or to not use bST. Obviously, a decision to not use bST to continue to supply milk to a marketing channel may bias the estimated return to the use of bST in those years when restrictions were placed on milk supplies. However, it should be assumed that before any bST restriction imposed, the farmer was shipping milk through the marketing channel that generated the highest net milk price. If that channel then required farmers to stop using bST, then the farmer would have to decide whether any available alternative milking channel would generate greater profits continuing the use of bST compared with ceasing bST use for the current channel. Unfortunately, the panel data does not include information on any bST restriction from shippers or any price premium that may have been paid to cease the use (or not use) bST over the $20 \mathrm{yr}$ of the data set.

A simple average of the annual results, including the statistically insignificant annual results even if positive, produced a cost reduction of $\$ 2.62$ per $100 \mathrm{~kg}$ of milk in 2013 dollars from the use of bST. McBride et al. (2004) estimated a difference in operating margin on US farms from the use of rbST to be $\$ 1.63$ per $100 \mathrm{~kg}$, but their estimate was not statistically different from zero, possibly because they only had data on 820 farms from the year 2000. A PSM estimate combining all years after converting costs into 2013 dollars produced a cost estimate reduction of $\$ 2.67$ when using bST. To place these reductions into perspective, in the year 2013, the total cost of production for all data farms averaged $\$ 48.35$, whereas hauling costs averaged $\$ 1.61$ per 100 $\mathrm{kg}$ of milk shipped. If the use of bST increased milk production per cow by the PSM estimate of $1,160 \mathrm{~kg}$, and the average production per cow for the non-bST users in the year 2013 was 10,169 $\mathrm{kg}$ per cow, then the additional profit from the use of bST at a cost reduction of $\$ 2.67$ per $100 \mathrm{~kg}$ would be $\$ 302.20$ per cow. A cost reduction of $\$ 2.67$ from an assumed base cost of production of $\$ 48.35$ would be a $5.5 \%$ reduction in cost and thus a $5.5 \%$ reduction in resources to produce a unit of milk.

A key requirement for a valid PSM measure is that the estimated probabilities of bST use must overlap between actual bST users and non-bST users, and that the probability mass must not occur at either zero or

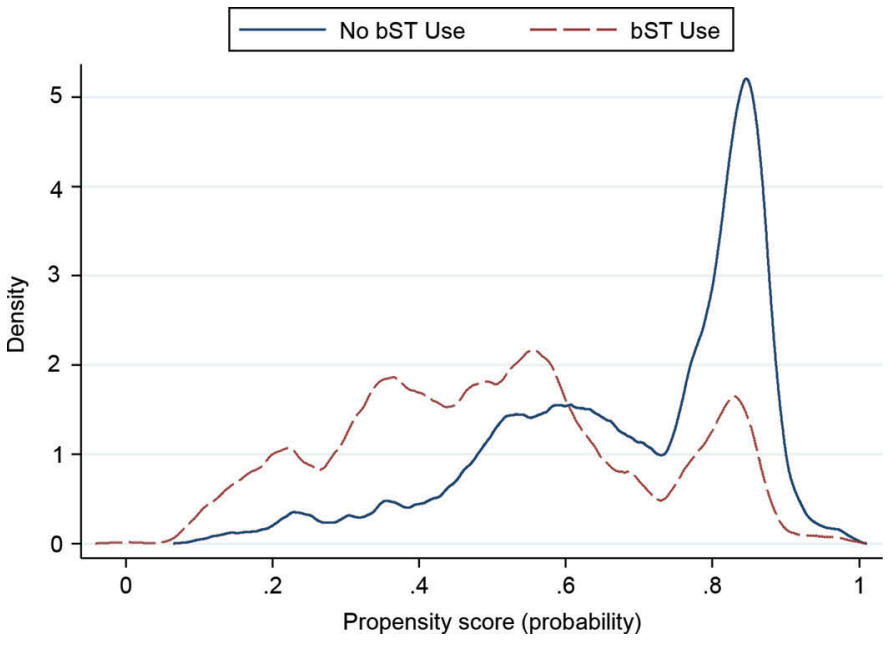

Figure 2. Propensity scores estimated by logistic regression using number of cows, milking system, barn type, age of the operator, and education of the operator. Color version available online.

one (Abadie and Imbens, 2012). Figure 2 contains plots of the bST and non-bST probabilities estimated from the logistic regression using a kernel density approach. These probabilities do overlap and are not massed at zero or one. In addition, matching is based upon the propensity scores rather than directly on the covariates used to arrive at the propensity score, so some suggest verifying balance on the covariates (Rosenbaum and Rubin, 1983). The Stata computer code "pscore" from Becker and Ichino (2002) was used to test for balance of the covariates. The number of cows and the barn type, which is correlated with the number of cows, were not balanced. However, given economies of size found in milk production (Mosheim and Lovell, 2009), it was deemed necessary to retain these variables in computing the propensity scores.

Another matching technique is to compare bST using and non-bST farms using a nearest neighbor approach using a distance measure. Given that more than one variable is used to match farms, a weighting matrix is needed to find closest matches. The distance measure used was the Mahalanobis, where the weighting index is a $\mathrm{k}$ by $\mathrm{k}$ diagonal matrix of the inverse sample standard errors of the $\mathrm{k}$ variables in the matching list (Imbens and Wooldridge, 2009). Using the same variables as were used in the PSM estimator (number of cows, milking system, barn type, age of operator, and education of operator) and no farms with more than 1,000 cows, with an additional exact matching by year, produced an estimate of a $\$ 2.78$ cost reduction in 2013 dollars when using bST, similar to the $\$ 2.67$ cost reduction estimate arrived at using propensity scoring. The nearest neighbor method can suffer from bias (Abadie and 
Imbens, 2011), but correcting for bias in this estimate using the same list of variables used for matching did not change the cost reduction estimate. The nearest neighbor approach is what Tauer (2009) used in an earlier version of this New York data when he arrived at an estimate of $\$ 1.61$ cost reduction in nominal dollars from the use of bST from 1994 through 2004, the first $11 \mathrm{yr}$ of bST use.

\section{CONCLUSIONS}

It is clear that bST is a cost-reducing technology. Over the 20 yr that this technology has been used by some of the dairy farms participating in the New York Farm Business Summary, annual decreases in the cost of producing milk ranged from $\$ 0.24$ (statistically zero) to as high as $\$ 3.42$ per $100 \mathrm{~kg}$ of milk produced, using PSM to estimate the treatment effect. Combining all years into one PSM model resulted in a cost reduction of $\$ 2.67$ per $100 \mathrm{~kg}$ of milk produced. Nearest neighbor matching resulted in a similar cost reduction estimate of $\$ 2.78$ per $100 \mathrm{~kg}$ of milk produced. Validity of these results, however, is conditional on biases from unobservables being not significant.

\section{ACKNOWLEDGMENTS}

I benefited from conversations with Jeffrey Gillespie (Louisiana State University, Baton Rouge), Jason Karszes (Cornell University, Ithaca, NY), and Wayne Knoblauch (Cornell University, Ithaca, NY). This research was funded exclusively by Cornell University.

\section{REFERENCES}

Abadie, A., and G. W. Imbens. 2011. Bias-corrected matching estimators for average treatment effects. J. Bus. Econ. Stat. 29:1-11.

Abadie, A., and G. W. Imbens. 2012. Matching on the estimated propensity score. Harvard University and National Bureau of Economic Research. Accessed Feb. 2, 2016. http://www.hks.harvard. edu/fs/aabadie/pscore.pdf.

An, H. 2013. The disadoption of rbST and its economic impact: A switching regression approach. Appl. Econ. Perspect. Policy 35:528-549.

Barham, B. L., D. Jackson-Smith, and S. Moon. 2000. The adoption of rBST on Wisconsin dairy farms. AgBioForum 3:181-187.

Becker, S. O., and A. Ichino. 2002. Estimation of average treatment effects based on propensity scores. Stata J. 2:358-377.

Caliendo, M., and S. Kopeinig. 2008. Some practical guidance for the implementation of propensity score matching. J. Econ. Surv. $22: 31-72$.

Capper, J. L., E. Castañeda-Gutiérrez, R. A. Cady, and D. E. Bauman. 2008. The environmental impact of recombinant bovine so- matotropin (rbST) use in dairy production. Proc. Natl. Acad. Sci. USA 105:9668-9673.

Cleveland, W. S. 1979. Robust locally weighted regression and smoothing scatterplots. J. Am. Stat. Assoc. 74:829-836.

Collier, R. J., M. A. Miller, J. R. Hildebrandt, A. R. Torkelson, T. C. White, K. S. Madsen, J. L. Vicini, P. J. Eppard, and G. M. Lanza. 1991. Factors affecting insulin-like growth factor-1 concentration in bovine milk. J. Dairy Sci. 74:2905-2911.

Dehejia, R. H., and S. Wahba. 2002. Propensity score matching methods for nonexperimental causal studies. Rev. Econ. Stat. 84:151161.

Dohoo, I. R., K. Leslie, L. Descôteaux, A. Fredeen, P. Dowling, A. Preston, and W. Shewfelt. 2003. A meta-analysis review of the effects of recombinant bovine Somatotropin: Methodology and effects on production. Can. J. Vet. Res. 67:241-251.

Foltz, J. D., and H. Chang. 2002. The adoption and profitability of rBST on Connecticut dairy farms. Am. J. Agric. Econ. 84:10211032 .

Gillespie, J., R. Nehring, C. Hallahan, C. Sandretto, and L. Tauer. 2010. Adoption of recombinant bovine somatotropin and farm profitability: Does farm size matter? AgBioForum 13:251-262.

Heckman, J., and S. Navarro-Lozano. 2004. Using matching, instrumental variables, and control functions to estimate economic choice models. Rev. Econ. Stat. 86:30-57.

Imbens, G. 2000. The role of the propensity score in estimating doseresponse functions. Biometrika 87:706-710.

Imbens, G. W., and J. M. Wooldridge. 2009. Recent developments in the econometrics of program evaluation. J. Econ. Lit. 47:5-86.

Khandker, S. R., G. B. Koolwal, and H. A. Samad. 2010. Handbook on Impact Evaluation: Quantitative Methods and Practices. The World Bank, Washington, DC. http://dx.doi.org/10.1596/978-08213-8028-4.

Knoblauch, W. A., L. D. Putnam, J. Karszes, T. Overton, and C. Dymond. 2012. Business Summary New York State 2011, R.B. 2012-01, Charles H. Dyson School of Applied Economics and Management, Cornell University.

McBride, W. D., S. Short, and H. El-Osta. 2004. The adoption and impact of bovine somatotropin on US dairy farms. Rev. Agric. Econ. 26:472-488.

Mendola, M. 2007. Agricultural technology and poverty reduction: A propensity-score matching analysis for rural Bangladesh. Food Policy 32:372-393.

Mosheim, R., and C. A. K. Lovell. 2009. Scale economies and inefficiency of U.S. dairy farms. Am. J. Agric. Econ. 91:777-794.

Rosenbaum, P. R., and D. B. Rubin. 1983. The central role of propensity score in observational studies for casual effects. Biometrika 70:41-55.

Rubin, D. 1974. Estimating causal effects to treatments in randomised and nonrandomised studies. J. Educ. Psychol. 66:688-701.

St-Pierre, N. R., G. A. Milliken, D. E. Bauman, R. J. Collier, J. S. Hogan, J. K. Shearer, K. L. Smith, and W. W. Thatcher. 2014. Meta-analysis of the effects of sometribove zinc suspension on the production and health of lactating dairy cows. J. Am. Vet. Med. Assoc. 245:550-564.

Stefanides, Z., and L. Tauer. 1999. The empirical impact of bovine somatotropin on a group of New York dairy farms. Am. J. Agric. Econ. 81:95-102.

Tauer, L. 2005. The impact of recombinant bovine somatotropin on dairy farm profits: A switching regression analysis. AgBioForum 8:33-39.

Tauer, L. W. 2009. Estimation of treatment effects of recombinant bovine somatotropin using matching samples. Rev. Agric. Econ. 11:411-423.

Tauer, L. W., and W. A. Knoblauch. 1997. The empirical impact of bST on New York dairy farms. J. Dairy Sci. 80:1092-1097. 